\title{
Angioplasty for the treatment of acute myocardial infarction
}

\author{
K J Beatt, F Fath-Ordoubadi
}

In principle, any innovative treatment that is to be accepted into clinical practice should be justified on the basis of the following criteria: a sound pathophysiological mechanism for its beneficial effect, safety and efficacy in the clinical setting, a financial cost that justifies the benefit to the targeted patient population, and the ability to apply the treatment in a practical manner. The first of these, encompassing the concept of early and sustained patency, provides the basis for understanding why primary angioplasty is so effective at treating acute myocardial infarction.

\section{Early patency}

The global utilisation of streptokinase and tissue plasminogen activator (t-PA) for occluded coronary arteries (GUSTO I) trial ${ }^{1}$ has shown the regimen of accelerated t-PA to be superior to other tested thrombolytic strategies in terms of achieving higher early patency and lower mortality. Perhaps more importantly the study demonstrated that suboptimal reperfusion with compromised flow is little better than an artery that remains occluded. ${ }^{2}$ The early (90 minute), complete (TIMI grade 3 flow), and sustained reperfusion of the infarct related artery are the most crucial factors in preventing death and impairment of cardiac function following an acute myocardial infarction. ${ }^{3}$ Even with optimal thrombolytic therapy only $54 \%$ of the patients eligible for thrombolytic treatment in the GUSTO I trial achieved early high grade patency. In contrast, current primary angioplasty studies show that reperfusion rates are generally greater than $90 \%$, and in some studies as high as $98 \% .^{4}$ Whereas improvements in time to thrombolytic treatment and new thrombolytic agents may significantly improve patency, it is unlikely to approach that achieved by primary angioplasty and may increase the risk of fatal or disabling strokes. The aggressive use of anticoagulants and antiplatelet agents has led to only a modest increase in arterial patency at the expense of an exponential increase in intracranial bleeds. ${ }^{5}$ There are now several clinical trials assessing treatments with new thrombolytics, antithrombins, and antiplatelet agents for acute myocardial infarction that have been prematurely terminated because of excessive bleeding. There is hope that newer agents will provide higher patency rates with an acceptable risk profile, but the use of these agents remains speculative, whereas the risk profile as well as the benefits for angioplasty are well documented.

\section{Sustained patency}

Having demonstrated a superior early patency rate, is the advantage of primary PTCA sustained? The reductions in recurrent ischaemia and the need for further hospital admissions have been striking and provide the basis for an effective one stop strategy for treating acute ischaemia (fig 1). The ability to assess the extent of the disease and to treat effectively on day 1 reduces the need for the traditional noninvasive investigations that may be repetitive, unreliable or frankly misleading in an appreciable number of patients.

Again the mechanism of benefit is through the maintenance of arterial patency. Repeat angiography has demonstrated that patients having primary angioplasty maintain patency better than those receiving thrombolysis and this is reflected in clinical outcome. In the Zwolle trial arterial patency at 20-80 days was $68 \%$ in the thrombolytic group and $91 \%$ in the angioplasty group $(P=0.001)$ with corresponding reinfarction rates of $19 \%$ and $3 \%$. $(P=0.001) .{ }^{46}$ The figures for the combined endpoint of nonfatal myocardial infarction and death was $28 \%$ and $7 \%$, respectively, giving a relative risk for thrombolysis compared with angioplasty of 4.3 (95\% confidence interval (CI) $2 \cdot 2$ to $8 \cdot 3$ ). The ability to discharge patients from hospital secure in the knowledge that a further unheralded event is unlikely is reassuring for both the patient and the physician.

\section{Current status of primary angioplasty}

The stimulus for the current interest in primary angioplasty came in 1993 from the landmark publications of the three prospective randomised trials, two from the United States ${ }^{78}$ and one from the Netherlands. ${ }^{4}$ More recently, the results of the GUSTO IIb angioplasty substudy have been reported. ${ }^{9}$ This is by far the largest of the completed trials recruiting 1138 patients from centres around the world representing a variety of experience and varying clinical practice. The study was powered to show a difference in the primary composite end point of death, non-fatal reinfarction, and disabling stroke at 30 days. The results show that this end point was reached in $9.6 \%$ of the angioplasty group and $13.7 \%$ of the accelerated t-PA group ( $P=0.033)$. Mortality was $5.7 \%$ and $7 \%$, respectively (NS). Eighty two per cent of those randomised to angioplasty received this treatment 3.8 hours following the onset of pain and 1.3 hours following randomisation. However, the success rate in terms of TIMI-3 flow was only $73 \%$. This was significantly lower than the $90 \%$ plus TIMI-3 flow achieved in other contemporary randomised trials and is highly relevant as mortality in the patients with TIMI-3 flow in the GUSTO IIb study was $1.6 \%$, while those with TIMI-0, 1, and 2 flows had a mortality increase of more than 10 -fold to $21 \%, 14 \%$, and $20 \%$, respectively. ${ }^{9}$ This is, perhaps, the 


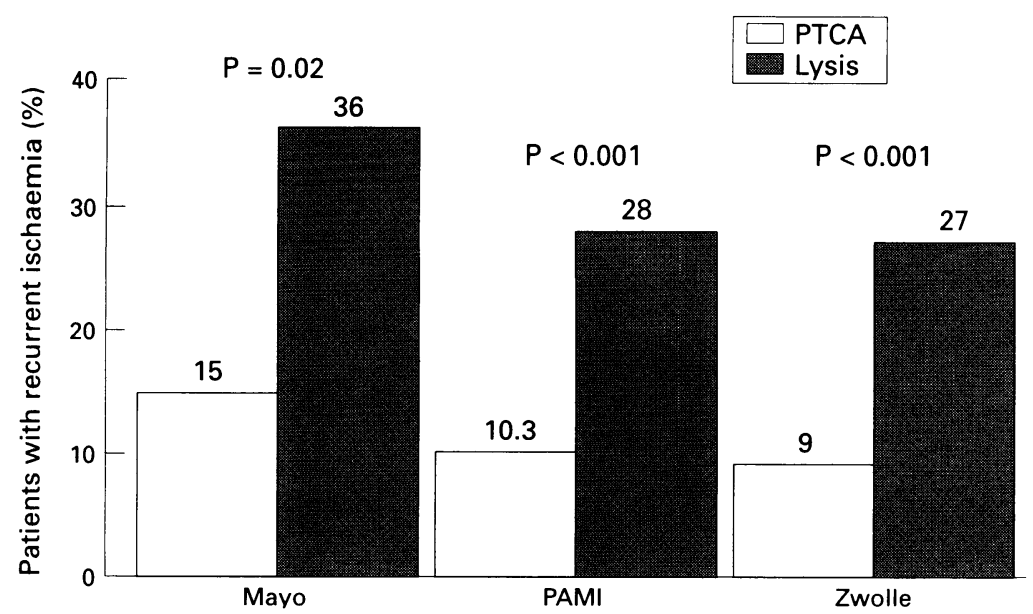

Figure 1 Incidence of recurrent ischaemia in three of the randomised trials comparing primary angioplasty with thrombolysis. ${ }^{478}$

most important message from this trial-in order for primary angioplasty to be an effective alternative to more conventional therapy a high early rate of TIMI-3 flow must be achieved.

An updated meta-analysis including this and nine other studies with a total of 2606 patients showed that patients undergoing PTCA had a mortality of $4.4 \%$ compared with $6.5 \%$ of patients receiving thrombolysis $(34 \%$ reduction, $P=0.02$ ), a death and non-fatal myocardial infarction rate of $7.2 \% v 11.9 \%$ ( $40 \%$ reduction, $P=0.0001)$, and for the important complication of haemorrhagic stroke, a rate of $0 \cdot 1 \% v 1 \cdot 1 \%$ (65\% reduction, $\mathrm{P}=0.0005) .{ }^{10}$ Figures from this analysis are combined with other studies to estimate the number of lives saved using a variety of contemporary treatments for acute myocardial infarction in fig 2 . However, the use of these figures, although compelling in themselves, considerably underestimates the true benefit

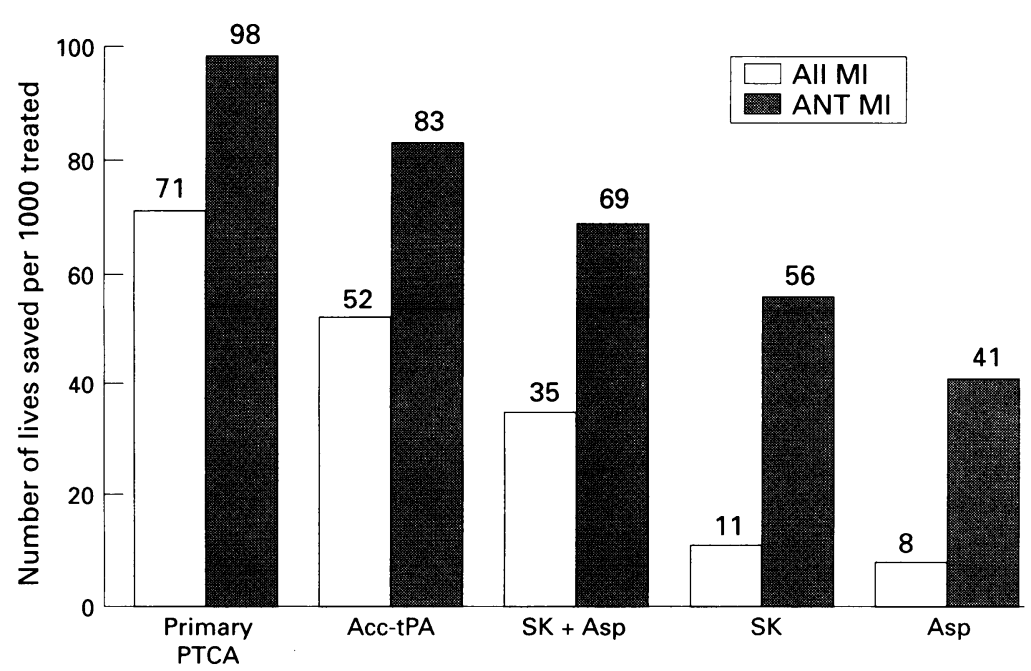

Figure 2 Comparison of number of lives saved per 1000 patients treated at 30 days following acute myocardial infarction (MI) for different reperfusion strategies and aspirin. Acc-tPA, accelerated $t P A ; S K$, streptokinase; Asp, asprin. The figures have been derived by taking the overall mortality rate in control patients as $11.5 \%$ for all MIs and $16.9 \%$ for anterior MIs (taken from FTT's collaborators study ${ }^{21}$ ). Mortality rate for primary angioplasty for the overall population and for anterior MIs was taken as $4.4 \%$ (from meta-analysis of primary PTCA $A^{8}$ ) and $7 \cdot 1 \%$ (taken from GUSTO II $b^{9}$ ), respectively; for accelerated $t P A$ as $6.3 \%$ and $8.6 \%$, respectively (taken from GUSTO $I^{\prime}$ ); for streptokinase with aspirin as $8 \%$ and $10 \%$, respectively; for streptokinase alone $10.4 \%$ and $11 \cdot 3 \%$; and for aspirin as $10 \cdot 7 \%$ and $12 \cdot 8 \%$, respectively (taken from ISIS-2 study $\left.{ }^{22}\right)$. of primary angioplasty in the total patient population, something that becomes apparent with a more critical analysis of the randomised trial in acute ischaemia.

\section{Limitations of randomised trials in acute myocardial infarction}

The results of well conducted randomised clinical trials are widely accepted as the most appropriate method of evaluating clinical practice. An important and overriding principle in the conduction and interpretation of these trials is that the recruited trial population should be a true sample population reflecting the characteristics of the population of interest, and ideally all patients should receive the treatment allocated at randomisation. Most recent studies assessing the effect of invasive investigation fall well short of meeting these criteria. Obtaining representative populations becomes particularly difficult once there is the perception, by either physician or patient, that one or other of the treatment arms is superior. In particular, those at highest risk are preferentially offered the "optimal' treatment and are therefore not recruited for the trial. This concept, which is self evident to those recruiting patients for trials, is often not appreciated by statisticians and non-involved commentators. Studies assessing the effects of thrombolytics in acute myocardial infarction have consistently selected a population at lower risk than the true myocardial infarction population; an observation that is confirmed by the comparatively low mortalities recorded in both treatment arms. ${ }^{11112}$ Recent intervention studies where records have been kept of the total population show that the sample population may be as low as $4 \%$ of recruitable population. Most studies do not document this important detail, which has major implications in the way the results are interpreted.

The problem is compounded by crossover from one treatment arm to another, which may be as high as $50 \%$ in some trials, and again will occur more frequently in the patients at highest risk. ${ }^{1314}$ In a recent study concluding that primary angioplasty offered no additional benefit compared to thrombolytic therapy, $30 \%$ of those receiving thrombolysis underwent angioplasty in the first 24 hours. ${ }^{15}$ This subgroup may influence the favourable outcome of the thrombolysis group, and a more appropriate conclusion from the dataset provided (which is also a selected dataset) would be to argue that the outcomes of patients receiving thrombolysis are similar to those having primary angioplasty if, and only if, immediate angioplasty is available to the thrombolytic group who most need it.

When assessing the true benefit of primary angioplasty, care should be taken to avoid using selected data from unrepresentative sample populations that fail to adhere to their randomised treatments. In this respect the Zwolle study deserves special consideration. Conducted at a time when there was genuine doubt concerning the benefit of primary angioplasty, it is unusual in that virtually all eligible patients admitted to hospital were 
recruited, irrespective of their underlying risk. A $50 \%$ reduction in mortality was demonstrated with primary angioplasty at a mean follow up of 30 months; a reduction considerably greater than the meta-analysis has determined. ${ }^{4}$

The point is further illustrated by analysing the subset of patients with the highest mortality. In the Primary angioplasty in myocardial infarction (PAMI) trial patients older than 70 years with an anterior myocardial infarction and a heart rate faster than 100 beats/min treated with thrombolysis had a mortality of $10 \cdot 4 \%$ compared to $2 \cdot 0 \%$ with angioplasty.

The current meta-analysis shows that although the relative mortality reductions are impressive they translate into only a modest absolute benefit because of low mortalities inherent in preferentially recruiting low risk patients into randomised clinical trials. However, critical analysis of the data available suggests that these relative reductions also apply to high risk patients, where the benefit becomes far more substantial than the figures that are quoted in fig 2 . The difficulties of performing randomised trials where interventional procedures are involved have forced trials designs that are impractical and difficult to implement according to protocol and may therefore not answer the relevant questions. In this situation more attention should be paid to the mechanisms of benefit and the surrogates of favourable clinical outcomes, avoiding the often heard cry for additional randomised trials, without full understanding of the limitations of their predecessors.

\section{Practical and cost issues}

As the data on the benefit of primary angioplasty has become favourable the arguments opposing the use of the procedure have centred on the costs and the difficulty of providing access for most if not all patients. The two most comprehensive primary angioplasty studies have shown that primary angioplasty is no more expensive than thrombolysis particularly if costs are adjusted for survivors and the expenses are considered over one year. ${ }^{1617}$ The higher initial cost of primary angioplasty is offset by the increased costs of re-admissions for recurrent ischaemia in the patients treated with thrombolysis. Further cost savings can be achieved by concentrating expertise so that more patients are admitted to fewer, more experienced units. The recognition that many of the traditional non-invasive tests become redundant following the initial determination of coronary anatomy and LV function will allow further refinement of postmyocardial infarction management with further efficiency and cost savings.

Most of the data on primary angioplasty comes from centres experienced in invasive procedures. Performing primary angioplasty is more demanding than the elective use of the procedure. It should be recognised that experience, expertise, and an adequate throughput of patients are essential components for achieving acceptable standards in primary angioplasty, as is the case for elective angio- plasty. A recent registry documenting primary angioplasty in 4625 patients showed that units performing more than 40 angioplasties annually for acute myocardial infarction demonstrated significantly better outcomes, ${ }^{18}$ while the GUSTO II trial showed improved results in centres performing more than 625 angioplasty procedures a year. ${ }^{7}$

\section{Implications for current practice}

Over the past 20 years angioplasty has developed from a crude technique limited in its application to the most common revascularisation procedure for coronary artery disease. It is broadly most effective at treating acute ischaemia, and the greatest mortality benefit is achieved treating acute myocardial infarction. There can no longer be disagreement that for many high risk patients, primary angioplasty offers a cost effective mortality benefit many times greater than conventional treatment. Even more compelling is the use of the procedure for treating patients in situations where there is no effective alternative-where thrombolysis is contraindicated or where complications develop as a result of failed thrombolysis. Units that are able to offer this treatment will achieve substantially better results than those that are only able to offer treatment with intravenous thrombolysis.

In 1971 the benefits of thrombolysis were demonstrated in a controlled randomised trial $^{19}$ and in 1985 an overview established the message beyond doubt. ${ }^{20}$ Yet it took many more years for the treatment to become established practice for all patients. There is now a need to evaluate a further change in treatment and to establish how this can be made available for those who most stand to benefit. The indicators are that with a willingness to change and an appropriate reallocation of current resources the necessary progress can be made.

1 The GUSTO Investigators. An international trial comparing four thrombolytic strategies for acute myocardial ing four thrombolytic strategies for acut
infarction. N Engl f Med 1993;329:673-82.

2 The GUSTO Angiographic Investigators. The effects of tissue plasminogen activator, streptokinase or both on coronary artery patency, ventricular function and survival after acute myocardial infarction. $N$ Engl f Med 1993; 329:1615-22

3 Fath-Ordoubadi F, Huehns TY, Al-Mohammad A, Beatt $\mathrm{KJ}$. Significance of the TIMI scoring system in assessing infarct-related artery reperfusion and mortality following acute myocardial infarction. Am Heart $\mathcal{F}$ 1997;133:60-6.

4 Zijlstra F, de Boer MJ, Hoorntje JCA, et al. A comparison of immediate coronary angioplasty with intravenous streptokinase in acute myocardial infarction. $N \mathrm{Engl} f \mathrm{Med}$ 1993:328:680-4.

5 The GUSTO II Investigators. Randomized trial of intravenous heparin versus recombinant hirudin for acute coronary syndromes. The global use of strategies to open Circulation 1994;90:1631-7.

6 Zijlstra F, de Boer MJ, Beukema, et al. Mortality, reinfarction, left ventricular ejection fraction and costs following reperfusion therapies for acute myocardial infarction. Eur Heart $\mathcal{f} 1996 ; 17: 382-7$.

7 Grines CL, Browne KF, Marco J, et al. A comparison of immediate angioplasty with thrombolytic therapy for acute myocardial infarction (PAMI group). $N$ Engl f Med acute myocardia

8 Gibbons RJ, Holmes DR, Reeder GS, et al, for the Mayo coronary care unit and catheterization laboratory groups. Immediate angioplasty compared with the administration of a thrombolytic agent followed by conservative treatment for myocardial infarction. $N$ Engl f Med 1993;328: $685-91$.

9 The GUSTO-IIb Angioplasty Subgroup Investigators. An international randomized trial of 1138 patients comparing primary coronary angioplasty versus tissue plasminogen activator for acute myocardial infarction. $N$ Engl f Med 1997;336:1621-8. 
10 Simes JR, Weaver DW, Ellis SG, Grines CL. Overview of the randomised trials of primary PTCA and thrombolysis in acute myocardial infarction [abstract]. Circulation 1997;94(suppl):I331.

11 ISIS-3 collaboration group. A randomised comparison of streptokinase vs tissue plasminogen activator vs anistrestreptokinase vs tissue plasminogen activator vs anistre-
plase and of aspirin plus heparin vs aspirin alone among plase and of aspirin plus heparin vs aspirin alone among
41,299 cases of suspected acute myocardial infarction. 41,299 cases of suspect
Lancet $1992 ; 339: 753-70$.

12 The GUSTO IIb Investigators. A comparison of recombinant hirudin with heparin for the treatment of acute coronary syndromes. $N$ Engl $f$ Med 1966;335:775-82.

13 RITA trial participants. Coronary angioplasty versus coronary artery bypass surgery: the randomised intervention treatment of angina (RITA) trial. Lancet 1993;341: 573-80.

14 TIMI IIIB investigators. Effects of tissue plasminogen activator and a comparison of early invasive and conservative strategies in unstable angina and non-Q-wave myocardial infarction. Results of the TIMI IIIB trial. Thrombolysis in myocardial ischemia. Circulation 1994;89:1545-56.

in myocardial ischemia. Circulation 1994;89:1545-56.
15 Every NR, Parsons LS, Haltky M, et al. For the MITI Every NR, Parsons LS, Haltky M, et al. For the MITI
investigators. A comparison of thrombolytic therapy with investigators. A comparison of thrombolytic therapy with primary coronary angioplasty for acute
tion. $N$ Engl $₹$ Med 1996;335:1253-60.

16 de Boer MJ, van Hout BA, Liem AL, Suryapranata $H$, Hoorntje JCA, Zijlstra F. A cost-effective analysis of primary coronary angioplasty versus thrombolysis for acute myocardial infarction. Am $\mathcal{F}$ Cardiol 1995;76:830-3.
17 Stone GW, Grines CL, Rothbaum D, et al. Analysis of the relative costs and effectiveness of pimary angioplasty versus tissue-type plasminogen activator: the primary angioplasty in myocardial infarction (PAMI) trial. $7 \mathrm{Am}$ Coll Cardiol 1997;29:901-7.

18 Zahn R, Vogt A, Neuhaus K-L, Schuster S, Senges J for the ALKK study group. Angioplasty in acute myocardial infarction in clinical practise: results in 4625 patients infarction in clinical practise: results in 4625 patients from the ALKK angioplasty reg
Cardiol 1997;29(suppl A):15A.

19 European Working Party. Streptokinase in recent myocardial infarction: a controlled multicentre trial. $B M \mathcal{F}$ 1971;3:325-31.

20 Yusuf S, Collins R, Peto R, et al. Intravenous and intracoronary fibrinolytic therapy in acute myocardial infarction: overview of results on mortality, reinfarction and side effects from 33 randomised controlled trials. Eur Heart $\mathcal{f} 1985 ; 6: 556-85$

21 Fibrinolytic Therapy Trialists' (FTT) Collaborative Group. Indication for fibrinolytic therapy in suspected acute myocardial infarction: collaborative overview of acute myor patis from all randomised trials of more than 1000 patients. Lancet

22 ISIS-2 (Second International Study of Infarct Survival) collaboration group. Randomised trial of intravenous streptokinase, oral aspirin, both, or neither among 17187 cases of acute myocardial infarction. Lancet 1988,ii: 349-60.

\section{Is primary angioplasty feasible or will we provide a two-tier service?}

\section{Pascal Chatelain, Philip Urban}

Primary angioplasty for acute myocardial infarction has its fans, its doubters, and those (the majority) who belong to neither camp because they have no choice other than thrombolysis to achieve myocardial reperfusion in their institution. Should they feel inadequate and guilty not to be in a position to offer the "best" treatment? Should they all start a hard and long fight with their administration for an increased share of scarce resources? In other words, should the clinical superiority of primary angioplasty, be used as an argument for the availability of catheterisation laboratories and interventionists in every hospital? A responsible answer to these questions should probably be negative.

To abandon thrombolysis as the treatment of choice for acute myocardial infarction would certainly be a mistake as it has several advantages over primary angioplasty. First, if appropriately prescribed, its administration by a general practitioner or a junior casualty doctor will be as effective as when given by the most experienced cardiologist. Second, thrombolysis can be administered out of hospital when geographical constraints make this necessary. ${ }^{1}$ Third, new thrombolytic agents are under investigation with the common aim to achieve TIMI-3 flow more rapidly in a larger number of patients. ${ }^{2}$

On the other hand, several advantages of primary angioplasty remain. Overall analysis of more than 2000 patients randomised in eight studies so far demonstrates a significant mortality reduction of angioplasty compared with thrombolysis, and the rare but devastating occurrence of intracerebral bleeding is also avoided. ${ }^{3}$ Coronary anatomy and left ventricular function are assessed immediately, allowing better therapeutic decisions including early discharge. ${ }^{4}$ The efficacy of reperfusion can be monitored directly and eventually modified by further mechanical and pharmaceutical interventions. Finally, this treatment allows the patient to be in expert hands during the acute phase of the disease.

However, recent multicentre data from the GUSTO IIb trial ${ }^{5}$ suggest that the overall differences between primary angioplasty and accelerated tissue plasminogen activator ( $t-$ PA) are rather small, and point to the need for subgroup analysis. High risk patients, and probably patients with a contraindication to thrombolysis, are emerging as those with the best indications for primary angioplasty.

After a rather unequal competition between both strategies during the first 10 years of the reperfusion era, an unpleasant and unjustified feeling of revenge has been perceptible behind several affirmations favouring primary angioplasty. We should stop competing and concentrate on the real issues. These include making primary angioplasty available for the subset of patients most likely to benefit from the procedure, and organising adequate referral networks. It must then be the responsibility of every physician to make the best decision after a thorough (but swift) evaluation of the individual patient's situation.

1 GREAT Group. Feasibility, safety, and efficacy of domiciliary thrombolysis by general practitioners: Grampian region early anistreplase trial. $B M \mathcal{F}$ 1992;305:548-3.

2 Fuster V. Coronary thrombolysis - a perspective for the practicing physician. $N$ Engl f Med 1993;329:723-5.

3 Michels KB, Yusuf S. Does PTCA in acute myocardial infarction affect mortality and reinfarction rates? A infarction affect mortality and reinfarction rates? A quantitative overview (meta-analysis) of the

4 Brodie B, Grines CL, Spain M, Griffin J, Balestrini C, Stone GW, et al. A prospective, randomized trial evaluating early discharge (day 3) without non-invasive risk ing early discharge (day 3 ) without non-invasive risk infarction: PAMI-2 [abstract]. $f \mathrm{Am}$ Coll Cardiol 1995; infarction: $\mathrm{PAN}$

5 The GUSTO-IIb Angioplasty Subgroup Investigators. An international randomized trial of 1138 patients comparing primary coronary angioplasty versus tissue plasminogen activator for acute myocardial infarction. $N \mathrm{Engl} \mathcal{F} \mathrm{Med}$ 1997;336:1621-8. 
vascular disease, risk factors, interventions, and prognosis, fulfilling criteria for a suitable non-invasive assessment of endothelial function. Furthermore, several groups have targeted this molecule as a means of intervening in the thrombotic process. ${ }^{16}$ The next five years will tell if this approach is successful.

The non-invasive approach outlined by Mullen and colleagues has provided invaluable opportunities to dissect the pharmacology of the endothelium. However, by its very nature such an approach is unlikely to provide epidemiological data or even data to compare groups with large numbers of subjects. We submit that plasma markers such as von Willebrand factor and soluble thrombomodulin are likely candidates for providing data of this nature.

ANDREW BLANN GREGORY LIP

Haemostasis, Thrombosis and Vascular Biology Unit, University Department of Medicine The City Hospital, Dudley Road, Birmingham B18 $7 Q H$, UK

1 Mullen MJ, Thorne SA, Deanfield JE, Jones $\mathrm{CJH}$. Non-invasive assessment of endothelial function. Heart 1997;77:297-8.

2 Lip GYH, Blann AD. Von Willebrand factor and its relevance to cardiovascular disease. Br Heart $\mathcal{f} 1995 ; 74: 580-3$.

3 Blann AD, Taberner DA. A reliable marker of endothelial cell dysfunction: does it exist? $\mathrm{Br}$ f Haematol 1995;90:244-8.

4 Badimon L, Badimon JJ, Chesebro JH, Fuster V. von Willebrand factor and cardiovascula disease. Thromb Haemostas 1993;70:111-18.

5 Greaves M, Pickering C, Knight G, Boulton ALM, Ball J, Ward JD, et al. Changes in the factor VIII complex in diabetic ketoacidosis: evidence of endothelial cell damage? Diabetologia 1987;30:160-5.

6 Van den Berg M, Boers GHJ, Franken DG Blom HJ, van Kamp GJ, Jakobs C, et al. Hyperhomocysteinaemia and endothelial dysfunction in young patients with peripheral arterial occlusive disease. Eur $₹$ Clin Invest 1995;25:176-81.

7 Thompson SG, Kienast J, Pyke SDM, Haverkate F. Hemostatic factors and the risk of myocardial infarction or sudden death in patients with angina pectoris. $N$ Engl $\mathcal{F}$ Med patients with angina

8 Blann AD, Miller JP, McCollum CN. Von Willebrand factor and soluble E-selectin in the prediction of cardiovascular disease progression in hyperlipidaemia. Atherosclerosis

9 Boffa MC. Considering cellular thrombomodulin distribution and its modulating factors can facilitate the use of plasma thrombomodulin as a reliable endothelial marker. modulin as a reliable endothelial masis 1996;26(Suppl 4):233-43.

10 Blann AD, Amiral J, McCollum CN. Circulating endothelial cell/leucocyte adhesion moleing endothelial cell/leucocyte adhesion molecules in ischaemic he

11 Seigneur M, Dufourcq P, Gin H, Delafaye C, Amiral J, Pruvost A, Boisseau MR. Plasma thrombomodulin levels increase with the severity of diabetic retinopathy. Blood Coag Fibrinolys 1994;5:845-6.

12 Blann AD, Amiral J, McCollum CN. Prognostic value of increased soluble thrombomodulin and increased E-selectin in ischaemic heart disease. Eur $\mathcal{f}$ Haem. [In press.]

13 Gearing AJH, Newman W. Circulating adhesion molecules in disease. Immunol Today 1993;14:506-12.

14 Blann AD, Seigneur M, Steiner M, Boisseau MR, McCollum CN. Circulating endothelial cell markers in peripheral vascular disease: cell markers in peripheral vascular disease: atherosclerotic disease. Eur $\mathcal{F}$ Clin Invest. [In press.]

15 Belch JJF, Shaw JW, Kirk G, McLaren M, Robb R, Maple C, Morse P. The white blood cell adhesion molecule E-selectin predicts restenosis in patients with intermittent claudication undergoing percutaneous transluminal angioplasty. Circulation 1997;95: 2027-31.

16 Ruggeri ZM. Inhibition of platelet vessel wall interaction. Platelet receptors, monoclonal antibodies, and synthetic peptides. Circulation 1990;81(Suppl 1):I35-9.

This letter was shown to the authors, who reply as follows.

We read with interest the letter from Drs Blann and Lip regarding the advantages and limitations of plasma markers of endothelial cell function. We share their interest in this area of research and its potential clinical application. We feel, however, that evaluation of nitric oxide mediated arterial physiology in large conduit arteries using the non-invasive techniques described ${ }^{1}$ may provide insight into the pathophysiology of vascular disease, be an early marker of endothelial injury, and a means of evaluating interventions early in the natural history of atherogenesis.

The value of these measures in predicting disease development and outcome is not known and is central to current research efforts. Our published data, however, indicate that this technique can be used to study endothelial function in large groups of subjects from early in childhood, to provide epidemiological data, compare groups of subjects with risk factors, and demonstrate beneficial response to interventions. ${ }^{2-5}$

M J MULLEN M E DEANFIELD

Great Ormond Street Hospital for Children NHS Trust, London WC1N $3 \mathcal{F H}$, UK

1 Celermajer DS, Sorensen KE, Gooch VM, Spiegelhalter DJ, Miller OI, Sullivan ID, $e$ al. Non-invasive detection of endothelial dysfunction in children and adults at risk of atherosclerosis. Lancet 1992;340:1111-15.

2 Leeson CPM, Whincup PH, Cook DG, Donald AE, Papacosta O, Lucas A, et al. Flow mediated dilatation in 9-11 year old children: the influence of intrauterine and childhood factors. Circulation. [In press.]

3 Celermajer DS, Sorensen KE, Bull C, Robinson J, Deanfield JE. Endotheliumdependent dilation in the systemic arteries of asymptomatic subjects relates to coronary asymptomatic subjects relates to coronary
risk factors and their interaction. $f \mathrm{Am} \mathrm{Coll}$ risk factors and their interac
Cardiol 1994;24:1468-74.

4 Sorensen KE, Celermajer DS, Georgakopoulos D, Hatcher G, Betteridge DJ, Deanfield JE. Impairment of endothelium-dependent dilation is an early event in children with familia hypercholesterolemia and is related to the lipoprotein (a) level. $\mathcal{f}$ Clin Invest 1994;93: 50-5.

5 Clarkson P, Adams MR, Powe AJ, Donald AE, McCredie R, Robinson J, et al. Oral L-arginine improves endothelium-dependent dilation in hypercholesterolemic young adults. $f$ Clin Invest 1996;97:1989-94.

\section{CORRECTION}

Pregnancy and congenital heart disease C M Oakley Heart 1997;78:12-14.

The first sentence of the section Atrial septal defects should have read:

"The only frailty of patients with unrepaired atrial septal defects is intolerance of blood loss that can force left to right shunting, to the sudden detriment of left ventricular and coronary flow."

And not as published. The error is regretted. 